\title{
Leadership Approaches and its Impact on Follower Development and Performance
}

\author{
Faria Kabir, Nafiza Islam
}

Senior Lecturer, Department of Business Administration, Stamford University Bangladesh

\begin{abstract}
Conceptualization and defining the term leadership as theory is still difficult. To reveal the concept of leadership one common practice can be followed that is describing leaders by using established theories and researches. The current discussion explores two aspects. First, it will show how different theories and researches rise ontological challenges to construct the framezork of leadership characteristic and its meaning. Second, in terms of methodological implications whether the selected theories are enough for measuring the role and importance of leadership in Sales Management. The study also determines whether the leadership model can increase sales performance for the organization. Thus the conclusion focuses on the growing importance of positive psychology of leadership concept and its implication in Sales Management.
\end{abstract}

Keywords: Leadership, Sales Management, Transformational Leadership, Servant Leadership, Trait Approach, Behavior Approach

JEL Classification Code: E31

\section{INTRODUCTION}

$\mathrm{L}$ eadership is one of the oldest preoccupations serving as an important driver of innovation for thousands of years. The search of particular personal qualities and capabilities of leaders to generate knowledge about leadership has been common thrust of human civilization. As (Kotterman, 2006) truly stated that effective leadership remains most misunderstood and important concern of human conditions. Another scholar added that (Wood, 2005) in management studies the nature and roles of leadership still creates a problem to understand and raised significant debate. So initially in defining leadership existing theories and researches are potential contributors. But according to Dickson, Hartog \& Mitchelson (Dickson, Hartog \& Mitchelson, 2003) leadership researches are confusing and complicated because there is no such agreed definition to constrict the boundaries of leadership. Again (Kotterman, 2006) argued that the definition or theory used to define its traits varies significantly in each study.

Definition of leadership has many aspects, yet it argues that the common purpose of leadership is about influencing and creating purpose. In other words leadership is a rational process through which people together attempting to accomplish change or make a difference to achieve a common good. Meanwhile, a true leader is one whose magnetic personality galvanize people to perform the organization goals effectively and shape the decision for the greater good of the organization.

Again the term sales management refers to the direction of sales force personnel. It is the attainment of an organization's sales goals in an effective \& efficient manner through planning, staffing, training, leading \& controlling organizational resources. Sales management can be defined as the systematic process involving the formulation of sales strategy through development of account management policies, sales force compensation policies, sales revenue forecasts, and sales plan.

Although sales management and leadership are undoubtedly two separate functions, none of them alone can bring the desired success to the organization. So both the functions are equally important to the achievement of organizational goals successfully.

The objectives of this study are,

- To define the term leadership and sales management,

- To determine the theory that can best define leadership characteristics,

- Identify the importance of leadership in sales management,

- To determine the barriers to implement leadership in sales management

The first section of this paper will shed the light on different aspects of leadership theories and research; the second phase will highlight the significance and limitations of various theories; third section will draw the attention on specific theory for understanding the phenomena of leadership and the concluding part will justify whether the selected theory are enough to construct the framework of leadership characteristic and also define the meaning of leadership effectively. At the later part of this paper the authors try to identify the role of leadership 
Asian Business Review, Volume 3, Number 1/2013 (Issue 5)

ISSN 2304-2613 (Print); ISSN 2305-8730 (Online)

in sales management and how different approaches are used successfully by sales leaders. Finally some recommendations are included to reduce the barriers in implementing leadership in sales management.

\section{THEORETICAL FramEWORK}

This is an exploratory research about the concept of leadership and its implication in sales management. The design of this study is descriptive in nature. The efforts have been made to construct the framework of the study is based on secondary source. To explore the concept of leadership and its impact on follower development specifically in Sales Management focused on different international refereed publications and contents of the websites of different organizations.

\section{LITERATURE REVIEW}

Due to the variations the essence of leadership reflects many things. Authors (Wood, 2005) point out that early approaches treated leadership on the basis of individual personality or traits which is known as the so called 'great man' or 'quality approach'. Some scholars found traits are not only predictor of leadership ability so soon they investigate other variable the behavior or style of leadership as author defined (Castro, Perinan, Bueno, 2008) that leader's influence on the work attitudes and behaviors of followers. Additionally, researchers asserted that effective leaders change their leadership style to fit the situation. Again Ayman's contingency approach focused on leader's attributes or style and leaders situational favorability (Ayman, Chemers \& Fiedler, 1995). The radical critique of mainstream theory and research often loss sight of the social identity and cross-cultural issues which is also focused by many authors debates. As authors (Dickson, Hartog \& Mitchelson, 2003) stressed that the variation of crosscultural dimensions is another common issue to find differences between cultures on leadership traits, characteristics and relationships.

Consequently, in organizational context most leadership theorists used the term leadership and management interchangeably which creates further confusion. It is true that leaders and managers both are important for organizations success because managers control and solve the problem while leaders motivate, inspire and produce potential change within organization. But (Kotterman, 2006) the ongoing debate between leadership and management generally remains unresolved so it is also a barrier for leadership theories. Moreover, some scholars defined leadership as a process and a property. The process focus on what leaders actually do and as a property leadership is the set of characteristics who are perceived to be a leader. Wood argued that leadership can be best understood as process rather than property or thing (Wood, 2005). The idea of 'process' actually conceived from the individual social identity of leaders because leaders obtain sense from the social process which formed through the past, present events and proceed in future events. Here, the author stressed that leaders are the outcomes of social process which also influenced the qualities of leaders. So, individual social actor is a perquisite for leadership.

In the light of the above discussion it is quite challenging to define leadership because researchers have produced various opinions regarding leadership. As the author provides a true opinion in this regard that 'Some see leadership as situational or contingent upon many factors. Others see leadership as a socially constructed phenomenon that is, what a leader is, and what a leader does, changes as society changes over time, or as we move from one culture to another.' (Clegg et al 2008).

However, from the discussion we can assume that leadership encompasses many things such as personal qualities, set of behaviors they possessed from social process, leaders also depend on situations and also influenced by cultural variables. Additionally, the overall leadership theories give us a guiding in shaping our views regarding leaders which are confusing and complex. So, it is more important to critically review whether these theories are sufficient to define leadership or any other specific theory responsible to define the leaders?

\section{TRAITS APPROACHES OF LEADERSHIP}

The early approaches of leadership theories focused on traits of leaders and used traits profiles as framework for evolving ideas of leadership. As (Kirkpatrick, Locke, 1991) stated that early in the $20^{\text {th }}$ century the "great man" theories basically based on traits theories. In these theories "traits" used as leader's specific abilities to lead. Evidence shows that there are specific set of traits that distinguish leaders from non-leaders, which include drive, honesty, self -confidence and cognitive ability (Kirkpatrick, Locke, 1991). Wood added the identity of leaders related with a set of distinguished qualities (Wood, 2003). Another author argued (Gill, 2003, that effective leaders motivate and inspire people through their credibility and credibility comes from leaders honesty and competence. Additionally these traits do matter to ensure effectiveness of leaders. For instance, self-confidence plays an important role in leader's decision making process and help to gain others trust even when the results of decision turns out to be poor, the self-confident leader use it as a learning opportunity. Again, cognitive ability of leaders such as intelligence can help leaders to formulate suitable strategies, solve problems and take correct decisions (Kirkpatrick, Locke, 1991). So, it can be assumed that successful leaders are not like other people and the leaders who possess the appropriate traits make successful implementation of actions.

However, these traits theories did not make assumption about whether leadership traits were inherited or acquired. During mid-century it was argued that no 
traits were universally associated with effective leadership and traits are not the only influential factors for successful business leadership. A prominent theorist perfectly concluded in this regard that "A person does not become a leader by virtue of possession of some combination of traits" (Kirkpatrick, Locke, 1991). Sternberg and Vroom argued that one is not simply borne intelligent, creative or specific potentials; many people with significant potential fail in some cases whereas others with lesser potential make the success. The same author also point out that sense of intelligence makes leaders to analyze and evaluate decisions but good analyst is not necessarily a good leader (Sternberg, Vroom, 2002). Thus traits theories give no guidance as to how much of any traits a person should have. Most of these traits are really pattern of behavior. In other words, rather than trying to figure out whom effective leaders are, researchers tried to determine what effective leaders do which are not enough to draw the actual meaning of leadership.

\section{BEHAVIOR APPROACHES OF LEADERSHIP}

Again, the behavior theorists tried to identify consistent relationships between leader's behaviors and employee response. The managerial grid theory of Blake and Mouton assumed that leadership effectiveness depends on two factors, they are concerned for people who focused human aspects or attitudes towards employees (friendship, helping co-workers) and concern for production emphasized on job centered leaders (greater output, cost effectiveness) (Bernardin, Alvares, 1976). Moreover, Ohio State Studies also highlighted leadership dimension as consideration (task centered) and initiating structure behaviors (employee centered) which are also similar of the concept of managerial grid theory (Bernardin, Alvares, 1976). These theories focused leaders effectiveness depends on ideal style of behavior. So, one conclusion can drawn from the both studies is that leadership style might not be onedimensional. Both task oriented and employee oriented are crucial factors for superior performance.

Consequently, Oshagbemi argued that leadership behavior theory creates confusion and appeared to be directionless because these theories put little consideration on both personal and organizational variables (Oshagbemi 2008). So the author asserted that it is useful to investigate the impact of the personal and organizational variables on leadership style rather considering only leaders behaviors. He explained that personal variables like age, gender, education are also important determinate. Education influences people values, wants; on the other hand age affects a leader's level of performance. More specifically, in comparing leadership styles and behavior between older workers and younger workers, evidence shows that younger workers are more willing to take risks and adjust with new initiative than older workers whereas older workers take minimum risks and use past experience in order to analyze new initiatives (Oshagbemi 2008). He stated that organizational variables such as size, type, hierarchy also can be used for effective organizational leadership (Oshagbemi 2008). But still the variables are not enough to define the leadership properly. However, researchers and authors using the traits and behavioral approaches showed that effective leadership depended on many factors. Unfortunately no one trait was common to all effective leaders. No one style or behavior was effective in all situations. In this case, attention turned to the study of situation and contingency model where leaders are assumed as the product of given situations.

\section{Contingency \& Situational Leadership}

Some scholars stressed on contingency model and evaluation of situational leadership due to conceptual ambiguous theories. Authors argued leadership behavior theories overemphasize leader's performance ability. In operation level relationship behavior creates difficulties. For instance, if the leaders spend a lot of time for convincing people for high relationship behavior it will cause inefficient use of leaders time (Graeff, 1997).

Fielder's contingency theory predicts two assumptions (a) the leader's basic motivational orientation (formally referred as leadership style) and (b) the degree to which the situation gives the leader control and influence (formerly referred to as situational favorability). The leaders orientation measured by scale referred as "least preferred coworker" (LPC) scale which used to identify the internal state of leader (Ayman, Chemers, Fielder, 1995). Fielder also added that it is conceptualized that leaders sense of influence and control afforded by the situation and the component of situation are leadermembership relationship, task structure and position power (Ayman, Chemers, Fielder, 1995). Thus the theory suggests that leadership style is essentially fixed and cannot change. Leaders cannot change their behavior to fit in a particular situation because the components of situation have been identified as contributors to a sense of predictability and control.

Similarly in Path-goal theory of leadership as part of contingency approach House focused the situational factors of personal characteristics of subordinates and environmental characteristics of workplace (Graeff, 1997). Path-goal theory emphasized that effective leaders helps to understand the employees, that they can fulfill their needs and expectation through job performance whereas commitment of providing employees sufficient feedback to complete the job is also an important factor for leaders effectiveness (Graeff, 1997).

Thus it is possible that individuals can learn how to diagnose a leadership in different situations. But contingent and situational theories often confusing, ambiguous and incomplete because the practitioner who attempt to apply situational leadership in the workplace 
Asian Business Review, Volume 3, Number 1/2013 (Issue 5) ISSN 2304-2613 (Print); ISSN 2305-8730 (Online)

may notice the conflicting guideline for the same situation which is difficult to implement (Graeff, 1997).

\section{Transformational, Transactional \& SERVANT LEADERSHIP}

Transformational and transactional leaders are individuals who have an exceptional impact on their organizations. According to Grisoni and Beeby, transformational leadership is a process with the individual capacities to satisfy the followers' needs for inspiration and empowerment, whereas transactional leadership also ensures followers' effectiveness through contingent rewards. Evidence shows that transformational leadership has a positive relationship with follower's development and performance whereas transactional leaders provide feedback, help to clarify desired outcomes from followers in exchange of rewards (Dvir, Avolio, Shamir, 2002). Consequently, authors addressed that there is an interesting relationship within the theory of transactional and transformational leadership. This interesting relationship is denoted as "falling dominoes effects" where the authors explain that transformational leadership is found in top-level in the organization because high-level leaders act as change agents through strategic decisions.

In contrast, middle and first-level leaders are transactional leaders who bring the changes through daily activities rather than strategic events (Oshagbemi, 2008). Another authors argued (Vera, Crossan, 2004) that transformational leadership builds on transactional leadership. It implies that leaders possess both transactional and transformational behaviors and use both of them when needed. Therefore, it becomes difficult to assess value laden leadership but it is evident that both leadership styles play a crucial role for contemporary thinking of leadership.

Consequently, the emerging servant leadership theory appears more relevant and timely in the above value laden leadership approach which highlighted that servant leaders not only provide service but also serve the people with total commitment. At the same time this model consists of six different dimensions such as voluntary nature of service, accountability and leading accurately; treating all followers equally and building personal bond marked by shared values, showing ethical justification and higher ideals, and promoting spiritual values and successfully interconnect internal and external world and finally positively transformed organizations and societies (Sendjaya, Sarros, Santora, 2008).

Thus the above theories have played an important role in the development of contemporary thinking about leadership. But when we are dealing with complex social systems composed of complex individuals, where relationships are consistently predictable, certainly no formula for success are dependable. So some author's argued that leadership is socially constructed and others focused leadership in cross-cultural context.

\section{SOCIAL IDENTITY \& CROSS-CULTURAL LEADERSHIP}

Since leaders are social actors, self identity of leaders are influenced by the social factors. At the same time leaders also deals with the diverse people from different social groups those who possessed dissimilar values, norms, attitudes. So it is important to understand the impact of social context on leadership. Authors identified that leadership requires not only a set of characteristics but also a property of a social system where leaders and followers share the process of enacting relationship (Gioia, Brown, 2002). Mason et al. emphasized on identifying groups within a social power structure where no group is holding equal status within a particular societal context. So leaders may face challenges to deals with the members of social identity groups who have been divided by race, religion, ethnicity, class (Mason, Ruderman, Weber, Ohlott, Dalton, 2007). Evidence shows that when societal conflicts occur between social identity groups within organizations leaders play the crucial role. It seems that organizational members turn to leaders for help because leaders are socially attractive to group members and they are strong influence on others. Group support with greater social status and prestige also increase the leader's power to influence (Mason, Ruderman, Weber, Ohlott, Dalton, 2007). Although another author strongly emphasized on the role of individual social actor which is considered as prerequisite of leadership, but the main drawback of social process often seem inexpressible and mysterious, and this theory focus more "I" context of leaders which creates a further problem to understand socially constructed leadership (Wood, 2005).

Similarly, it is rational to think that cultural differences will significantly influenced leadership traits and relationship with followers. So, several theorists have examined cross-cultural context of leadership. Authors defined (Dickson, Hartog, Mitchelson, 2003) the framework for studying cultural dimensions of leadership includes Schwartz, Trompenaars and Hampden-Turner, Kluckhohn and Strodtbeck, GLOBE study. But it is important to acknowledge that the leadership in cross cultural context primarily developed on the basis of Hofstede well-known study of cultural dimensions (individual-collectivism, masculinity-feminity, uncertainty avoidance, and power-distance and future orientation).

For in-depth understanding of cross cultural context of leadership we can focus on specific example that is "power distance" where scholars identified that in high power distance cultures the leaders are more rely on organizational rules and policies for laminating order and productivity (Mason, Ruderman, Weber, Ohlott, Dalton, 2007). Additionally, the GLOBE study demonstrated that cultures that are relatively high on 
power distance like Mexico and Taiwan prefer directive leadership whereas cultures relatively low on power distance such as United States and South Korea, participative leadership had positive effects on job satisfaction and commitment (Dickson, Hartog, Mitchelson, 2003). Therefore, it is evident that border aspects of cultures shape leaders behaviors, traits which equally important to framing leadership at the same time authors noticed that cross cultural leadership still confusing because researchers focused comparison of leadership in different cultures but less concentrated with low leaders interact with cross cultural context ( Dickson, Hartog, Mitcheison, 2003).

Thus, the notion of leadership evolves with various concepts. So we can define leadership as process, because leaders influence to shape the groups or organizational goals, motivate behavior toward the achievement of those goals and define group or organizational culture. On the other side leadership is property and process because it includes is set of characteristics or behaviors of individuals which are essential to be a leader in considering social and cultural influences. More specially, "the leaders exists to serve those whom he nominally leads and for those who supposedly follow him" and the main principal aim of leaders is helping the efforts of followers so that they can fulfill their goals and ensure success (Fondas, 1997).

Now we can conclude that all the leadership theories plays an important role for framing the concept and characteristics of leadership but if we review the inherent drawbacks of each theories creates further confusing such as First of all the traits or "great men" approach signify that "great men were born not made" but complete story of leadership involves more than just specifying leaders traits. Because traits are potential for leaders so to utilize these potential leaders considers additional factors which is less focused (Kirkpatrick, Locke, 1991). Second, behaviorist theory tried to identify consistent relationship between leader behavior and employees responses without considering situational impact (Bernardin, Alvares, 1976). Third, the contingency model basically designed to predict group performance and focused on "leader-situation" match at the same time LPC scale interpret that the interaction of leaders with favorable situations increase group productivity but other factors associated with productivity such as loyalty, satisfaction, commitment are less emphasized in this model (Ayman, Chemers, Fielder, 1995). Fourth, in situational leadership the situational variables are also confusing, controversial and logically inconsistent because it is difficult to predict appropriate guideline for situational control (Graeff, 1997). Fifth, transactional leadership stressed on followers goals achievement but do not encourage them for their greater development (Dvir, Eden, Avolio, Shamir, 2002). So due to theses significant complexities the growing concern for positive psychological empowerment of leadership becomes imminent in this situation. It is noticeable that psychological empowerment would enhanced through transformational behavior. Transformational leaders can play a crucial role for stimulating transformational behavior. In spite of the major contribution of other theories discussed in this paper, the main reason of focusing transformational leadership because the principal aspect of this theory emphasized on followers development (Dvir, Avolio, Shamir, 2002). So, it is obvious to think that if the leaders help the followers to reach the full potential and motivate them to transform their characteristics then they can perform their best to achieve the overall organizational effectiveness.

However, authors (Sendjaya, Sarros, Santora, 2008) argue that transformational leaders increased motivation and commitment of followers which will not necessarily benefit followers, as there is nothing in the transformational leadership model that says leaders should serve followers for the good of followers. But the same authors also point out that the role of servant leaders is to serve the followers whereas the role of transformational leaders are not only to serve the followers but also inspire them to achieve organizational goals (Sendjaya, Sarros, Santora, 2008).

But in our point of view, the transformational leadership has occupied the center stage in leadership research. But these explanations are not sufficient to build conceptual framework of leadership so the other rational facts needs to be addressed to justify the growing concern for transformational leadership.

\section{GROWING IMPORTANCE OF TRANSFORMATIONAL LEADERSHIP}

First, transformational leadership integrate follower's development through motivation. Evidence shows that transformational leaders are positively associated with motivation. It insists individual to take risks and make flexible to the changing situation (Kirk, Dijik, 2007). Furthermore, transformational leaders put extra effort to fulfill the dormant needs of followers which actually generate higher level of motivation (Dvir, Eden, Avolio, Shamir, 2002). Second, transformational leaders has a positive impact on followers empowerment and morality they enhance followers capacity of thinking new ideas, develop the ability of self management, these leaders can use empowerment to create a perception that followers are valuable members of the organization (Castro, Perinan, Bueno, 2008) again authors added that transformational leaders helps to increase individuals as well as organizational moral values (Dvir, Eden, Avolio, Shamir, 2002). Third, various studies show that transformational leaders have positive effects on attitudes and behaviors of followers. Here, attitudes refer leaders socialized charisma to attract followers and let them feel loyal, trustworthy towards their leaders. On the other side behaviors refer 
Asian Business Review, Volume 3, Number 1/2013 (Issue 5)

ISSN 2304-2613 (Print); ISSN 2305-8730 (Online)

charismatic action of the leaders that develop a collective sense of mission and purpose among the followers and by utilizing effective attitudes and behaviors transformational leaders increase job satisfaction and organizational commitment of employees (Castro, Perinan, Bueno, 2008). Fourth, scholars suggested that if the organization transforming themselves into learning, self-management, empowerment and ensure participative management style which considered as fundamental factors of transformational leadership theory then it will obvious that organization can increase its competitiveness (Fondas, 1997).

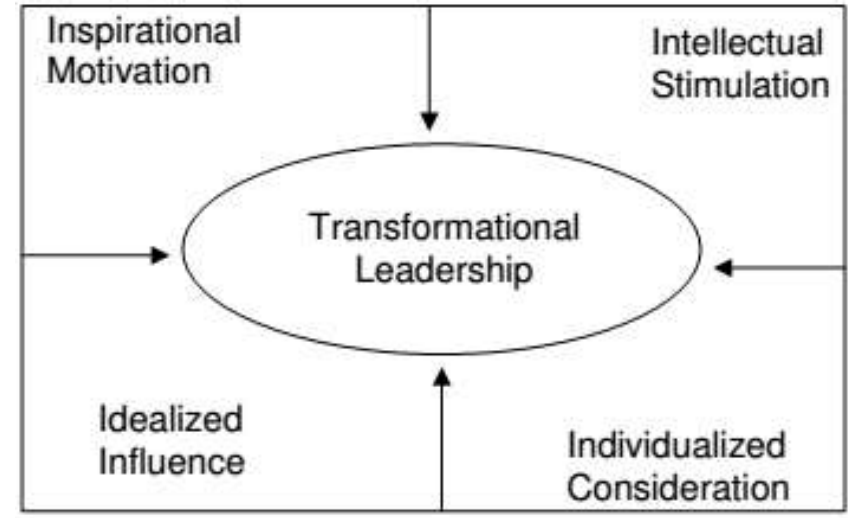

Figure 1: Impact for transformational leadership on followers

Fifth, author suggested that transformational leadership behavior balance between explorations refers to (search, variation result from decentralization, loose cultures, etc) and exploitation means (efficiency, improvement, increase control, etc) which finally helps to obtain superior performance in organization (Jansen, George, Bosch, Volberda, 2008) the same authors also added transformational leaders carefully manage performance based incentives by recognizing and rewarding on values for fairness and trust of followers (Jansen, George, Bosh, Volberda, 2008). Finally, transformational leadership also facilitate effective organizational learning (Vera, Crossan, 2004). So, this leadership theory ensures followers as well as organizational development.

\section{FIND A LEVERAGE OF SALES AND LEADERSHIP}

In the knowledge and information age, sales managers need to be leaders and coaches not just organizers and controllers. There is a need to balance leadership with management, creativity with control and people with output. The information age executive needs to "create the how" by facilitating people and processes via enlightened 360 degree leadership with a strong customer orientation.

Today Sales Managers usually have two roles. First, they have to manage and administer the sales team. Second, they are also expected to demonstrate Leadership of the sales team. Most Sales Managers are trained in the management and administration skills, but few are taught Leadership. They are simply expected to Lead - a very poor and risky strategy. Again an essential sales leadership role is to establish a sense of purpose or vision and clear direction. Senior sales managers are responsible for translating the overall business plan and marketing plan into a sales plan, using their own strategic analysis. Some authors recommend that a customer portfolio analysis model, modified by an understanding of each customer's purchasing strategy (Fiocca, 1982; Rogers, 2007) should inform the sales plan. When the business landscape changes, many sales leaders try to carry on as business as usual. However, this move leaves the business vulnerable. Instead, this is the time to reassess sales leadership and sales team. In both cases, leader's goal is to reposition both skill sets and mindset for the emerging marketplace. That's where assessments can be a tremendous value. They help to get a grip on the unique gifts and talents of leadership and sales teams that are needed to leverage moving forward. In addition, they can reveal weaknesses hidden that have potential to sabotage the leader's effectiveness. More than ever today, business executives have to operate as both leader and follower in the daily rounds of their job. Those who study leadership begin to take more interest in the 'psychological contract' between leader and followers. In other words, they began to ask what makes people prepared to follow one leader and unwilling to follow another. With few exceptions, this is as true of the corporate world as it is of military and political leaders. Aristotle noted: "He who has never learnt to obey cannot be a good commander". These ideas are now changing both the way we think about leadership and the style of our leaders. This is in tune with other social and organizational developments, including the move to more participative management and the rise of industrial democracy. Similarly, sales leaders need to take inventory of both their strengths and weaknesses, asking for support in areas in which they are weakest. Even the best of sales managers will have a hard time going it alone in today's market. When times get tough, there is a tendency for leaders to walk around looking like an austere, impenetrable fort, conveying strength to the troops. This tough guy attitude only isolates leaders further by making them less approachable. Real leaders let the guards fall and open up in tough times. They acknowledge and appreciate that they need support.

\section{ROLE OF TRANSFORMATIONAL LEADERSHIP IN SALES PLANNING AND IMPLEMENTATION}

From the above discussion it has been proved that leadership is a requirement to any successful business because the nature of good leadership is that it provides important direction to an organization. But one thing that leaders need in order to be leaders is Followers. Forcing people to be the followers will never work, but 
there are things that a leader can learn, and practice and do that will make people willing to follow him or her.

In sales oriented business organization sales leaders provide the environment for solutions but not necessarily the solutions. They create solutions from the collective intelligence of the team pulling players together \& planning the ability to listen to one another, the ability to learn from one another. The successful sales leader can define a mission that inspires the sales person, set realistic expectations, develop \& teach a tactical plan. Successful business leaders and sales managers understand the power of a culture and values in which everyone understands how their work contributes to the company achievements and bottom line sales results. These leaders lead for the benefit of the company, openly sharing credit for success with their teams.

Transformational leadership engagement is a simple concept with a payoff in greater financial performance, increased employee retention and increased productivity. These results attest to a need to be part of something great, something more than any person could achieve alone. At its highest level through engagement leaders can help managers and their front-line employees grasp their importance through thoughtful, steady communication in various ways.

In a more competitive environment, misguided sales organizations have driven their sales teams harder and harder in an effort to meet sales performance goals, ultimately leading to burnt out and de-motivated salespeople. These disengaged employees often lead to disengaged clients. Servant leadership can help realign the moral compass and put back on the path to higher sales performance. The proven path to servant hood is easy

to

follow.

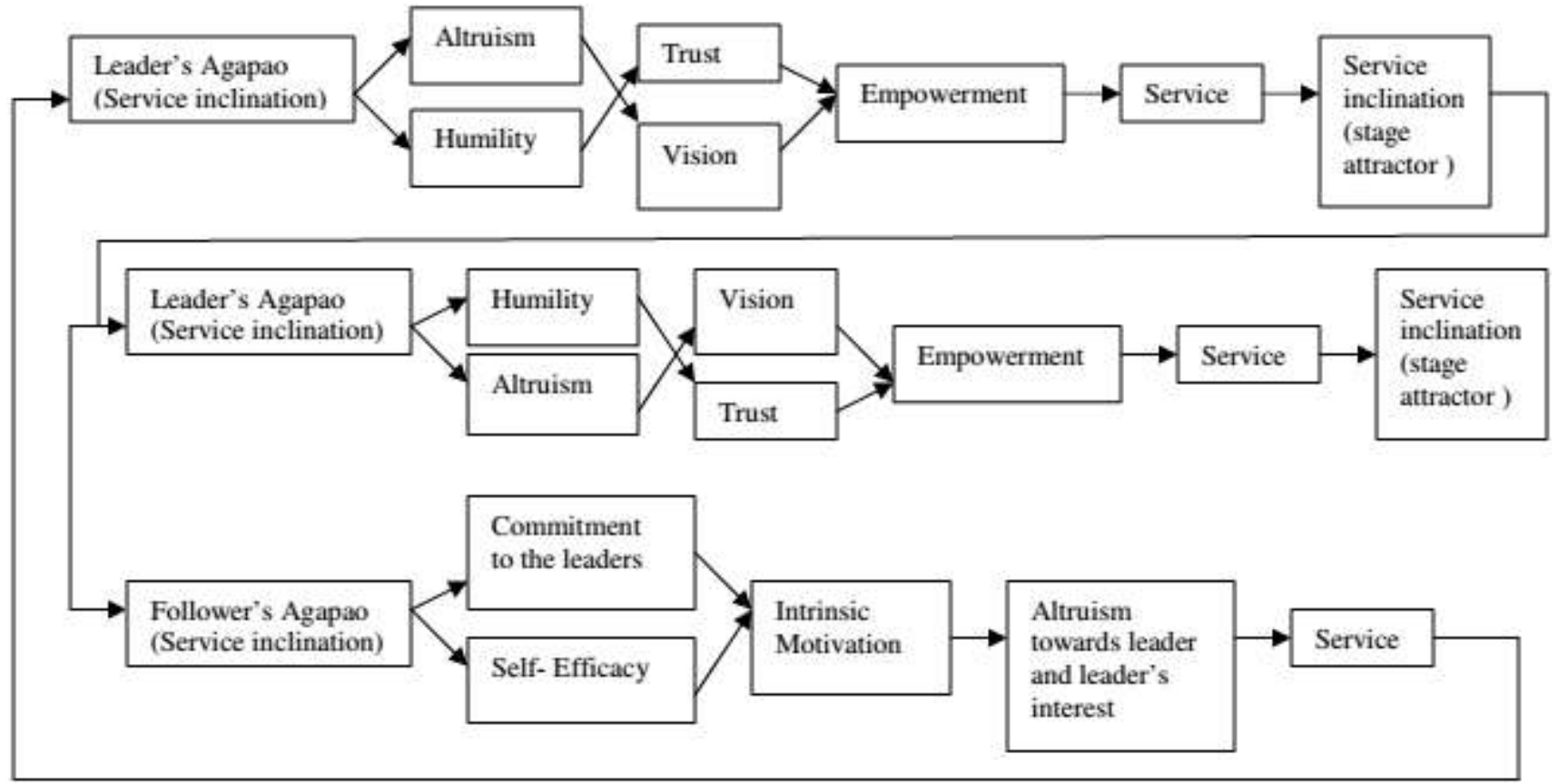

Figure 2: Chaotic servant leadership model built from Patterson (2003), Winston (2003) servant leadership model.

Start by putting serving first. Turn the sales force into "passionate advocates" of supporting, advancing and meeting your goals. We can take a look of some successful organization which has already achieved success in their sales using the servant leadership. The success of companies that are led by servant leadership should be enough to entice most sales leaders to take a closer look. AT\&T and Starbucks can be uttered in this regard. In fact, servant leadership aligns with the key model, the $4 \mathrm{R}$ Model of leadership. This model emphasizes that relationship with co-workers, managers, clients and peers are a first step in delivering sales Results. Starbucks was a medium-sized business realizing healthy sales growth when its leaders started to practice servant leadership. The former CEO of Copyright (C) 2013, Asian Business Consortium | ABR
Starbucks helped build Starbucks into the world's largest coffee chain on a culture of customer service and a dedication to servant leadership. By serving customers, Starbucks makes deeper connections and more sales. Starbucks shares another important lesson about servant leadership is to teach followers about how to lead themselves. Servant leaders set an example for their followers where one guided by core values and then empowers followers to lead themselves and others. Stew Leonard (2006), the owner of a super market had developed an approach to customer service Rule\#1: The customer is always right. Rule\#2: If the customer is ever wrong, reread Rule\#1! This approach toward customer has taken Leonard from a small dairy store to a highly profitable four-store supermarket in Connecticut and 50 | $P$ a g e 
Asian Business Review, Volume 3, Number 1/2013 (Issue 5) ISSN 2304-2613 (Print); ISSN 2305-8730 (Online)

New York. Basically servant leadership creates customer loyalty and increase customer lifetime value.

\section{BARRIERS TO LEADERSHIP IN SALES MANAGEMENT}

The true mark of a leader is to recognize the skills that are already present within him/her and be able to (1) Hire the best people who possess the expected skills and (2) train the entire group to work as a team and (3) Plan to go the long way. This is true and applicable for not only in sales management but also in every business organizations. But in doing that leaders generally faced some problems. One of the myths of leadership is the "blood \& guts" idea of leaders. Leadership at one time in the development of the industrial revolution was all about authority and command and control. But it went out the door in American business with the failures of the US car industry in the 1970's and 1980's. Richard Gorham (2003), the founder and President of LeadershipTools, Inc. has identified three barriers to sales that are directly related to leadership. These are:

a) Attitude Barriers

b) Behavioral Barriers

c) Conceptual Barriers

Attitude barrier tells that employees may have poor or non-productive attitude which they are not willing to correct, and this attitude is harmful for the individual and the organization as well. The impact becomes intense when the leader sanctions or ignores those attitudes. Behavioral barriers refer to an employee not completing sales management tasks as expected. This barrier hinders the achievement of maximum results. Conceptual barriers are the barriers that are difficult to overcome because these are predetermined beliefs of an employee planted at a very early age of their life. Basically conceptual barriers occur when the employees' beliefs are confronting with the existing culture in the workplace.

A survey on Male \& Female Middle \& Top Managers by Fortune Magazine (1995) results that $91 \%$ of women \& $75 \%$ of men believed that the existence of a maledominated corporate culture is the single most important barrier for women. Some studies have also found some gender differences in leadership style. This gender difference reduces the productivity of female sales people when they have to work under the supervision of male, this can be same for male also. There are some other limitations of sales leadership such as salespeople who have disruptive influence on others can create problems, conflicts of interest between sales people and leader, termination of employment, etc.

\section{Recommendations \& Conclusion}

Scholars rightly say indeed, that what leaders do and say as profound influence upon the world. Leaders influence others and make life fulfilling, influenced enriched and empowered. But the ongoing discussion and different perspectives of leadership theorist also throw the challenges to develop or identify a way of conceptualization the concept of leadership where we can ask can leadership be understood in different ways? More specifically after evaluating all the aspects of leadership theory it is confusing to develop the actual meaning. If leadership considered as trait theory then literature failed to provide enough evidence to stick to with the trait approaches. Behavioral theory being leaders are judge from their behaviors but not from their traits. As behavioral theory wasn't sufficient enough situation and contingency theory came up together with an emphasis upon transformational, transactional \& Servant leadership theory to envisage and implement change. To develop and help implement what came up with the positive psychological approach to leadership brining change to leadership perception. Thus could be seen that all the theories hold equally importance though with drawbacks of its own, no matter what sort of limitations we faced but there would always remain the concept of leadership is complicating when we put it to think. But at the same time it has also seen that through the successful use of transformational and servant leadership different organizations have already achieved successes. Even though different scholars also suggested that the existing models of leadership needs to be extended to get better outcomes.

In order to leading the sales team successfully, the leaders have to overcome these barriers. To overcome attitude barriers, the leaders' responsibility is not to sanction or ignore this kind of attitude rather to take necessary steps to rectify it. However, in dealing with behavioral barriers, success of sales leaders lies on teaching employees about the expected behavior (action), coach them to build their confidence and hold employees accountable for completing the desired behaviors on a consistent basis. Again, the leaders must gather knowledge regarding the predetermined belief system of employees to deal with attitude barriers. As a mentor of the sales team the leader must be unbiased, act like the guardian of his/her team.

\section{REFERENCES}

Ayman, R., Chemers, M. M. and Fiedler, F. (1995); The contingency model of leadership effectiveness: its level of analysis, Leadership Quarterly, pp.147-167.

Bernardin, H. J. and Alvares, K. M. (1976); The Managerial Grid as a Predictor of Conflict Resolution Method and Managerial Effectiveness. Administrative Science Quarterly, pp. 84-92.

Brown, M. E. And Gioia, D. A. (2002); Making things click Distributive leadership in an online division of an offline organization. The Leadership Quarterly, pp. 397-419.

Castro, C. B., Perinan, M. M. V. and Bueno, J. C. C. (2008) Transformational leadership and followers' attitudes: the mediating role of psychological empowerment. The 
International Journal of Human Resource Management, pp.1842-1863.

Chrobot-Mason, D., Ruderman, M. N., Weber, T. J., Ohlott, P. J. and Dalton, M. A. (2007) Illuminating a crosscultural leadership challenge: when identity groups collide. International Journal of Human Resource Management, pp. 2011-2036.

Dickson, M.W., Hartog, D. N. D. and Mitchelson, J. K. (2003) Research on leadership in a cross-cultural context: Making progress and rising new questions, The Leadership Quarterly, pp.729-768.

Eden, T. D. D., Avolio, B. J. And Shamir, B. (2002) Impact of Transformational Leadership on Follower Development and Performance: A Field Experiment. Academy of Management Journal, pp.735-744).

Elezovic, M. (2009) The Role of Leadership in Marketing Religious Organizations. Retrieved from http:/ / www.religionomics.com/asrec/ASREC09_Pape rs/Elezovic

Fondas, N. (1997) Feminization Unveiled: Management Qualities in Contemporary Writings. Academy of Management Review, pp. 257-282.

Gill, R. (2003) Change management-or change leadership? Journal of Change Management, pp.307-318.

Graeff, C. L. (1997) Evolution of Situational Leadership Theory: A Critical Review. Leadership Quarterly, pp.153170.

Grisoni, L. and Beeby, M. (2007) Leadershir, Gender and Sense-making. Gender, Work and Organization,pp.191209.

Jansen, J. J. P., George, G., Van Den Bosch, F. A. J.and Volberda, H. W. (2008) Senior Team Attributes and Organizational Ambidexterity: The Moderating Role of Transformational Leadership. Journal of Management Studies, pp. 982-1007.

Kark, R. And Dijk, D. V. (2007) Motivation to lead, motivation to follow: the role of the self-regulatory focus in leadership process. Academy of Management Review, pp. 500-528.
Kirkpatrick, S. A. and Locke, E. A. (1991) Leadership: do traits matter? Academy of Management Executive, pp. 4860 .

Kotterman, J. (2006) Leadership Versus Management: What's the Difference? Journal for Quality $\mathcal{E}$ Participation, pp.13-17.

Oshagbemi, T. (2008) The impact of personal and organisational variables on the leadership styles of managers. The International Journal of Human Resource Management, pp.1896-1910.

Rahman, A.S, Rubel, B.R, Rimi, N.N, (2007) Leadership Practices in Successful Project Management, Stamford Journal of Business Studies, Volume-2. July December 2007.

Rennaker, M. (2005) Servant Leadership: A Chaotic Leadership Theory, Servant Leadership Research Roundtable - August 2005. Retrieved from http://www.regent.edu/acad/sls/publications/confer ence_proceedings/servant_leadership_roundtable/200 5/pdf/rennaker_servant.pdf

Schul, L.P. (1987) An Investigation of Path-Goal Leadership Theory and Its Impact on Intrachannel Conflict and Satisfaction, Journal of Academy of Marketing Science, winter, 1987, Vol-15, No.4, 042-052.

Sendjaya, S., Sarros, J. C. and Santora, J. C. (2008) Defining and Measuring Servant Leadership Behaviour in Organizations. Journal of Management Studies,pp.402424.

Sternberg, R. J. and Vroom, V. (2002) The person versus the situation in leadership. The Leadership Quarterly pp. 301323.

Stew Leonard's, Hoover's Company Records, May 1, 2006, p 104226; www.stew-leonards.com/html/about.cfm, October 2006.

Vera, D. And Crossan, M. (2004) Strategic Leadership and Organizational Learning. Academy of Management Review, pp. 222-240.

Wood, P. (2005); The Fallacy of Misplaced Leadership. Journal of Management Studies, pp. 1101-1122. 